\title{
Why Are People Afraid of the Dentist? Observations and Explanations
}

\author{
Laura Beaton $^{\mathrm{a}}$ Ruth Freeman ${ }^{\mathrm{a}}$ Gerry Humphris ${ }^{\mathrm{b}}$ \\ ${ }^{a}$ Dental Health Services Research Unit, School of Dentistry, University of Dundee, Dundee, and b Health Psychology, \\ School of Medicine, University of St Andrews, St Andrews, UK
}

\section{Key Words}

Dental anxiety · Dental phobia · Aetiology

\begin{abstract}
Objective: The aim of this review was to explore the peerreviewed literature to answer the question: 'Why are people afraid of the dentist?' Method: Relevant literature was identified by searching the following on-line databases: PubMed, Psyclnfo, the Cochrane Library and Google Scholar. Publications were extracted if they explored the causes and consequences of dental fear, dental anxiety or dental phobia. $R$ esults: The research evidence suggests that the causes of dental fear, dental anxiety or dental phobia are related to exogenous factors such as direct learning from traumatic experiences, vicarious learning through significant others and the media, and endogenous factors such as inheritance and personality traits. Each individual aetiological factor is supported by the evidence provided. Conclusions: The evidence suggests that the aetiology of dental fear, anxiety or phobia is complex and multifactorial. The findings show that there are clear practical implications indicated by the existing research in this area: a better understanding of dental fear, anxiety and phobia may prevent treatment avoidance.
\end{abstract}

(c) 2013 S. Karger AG, Basel

\begin{tabular}{ll}
\hline KARGER & $\begin{array}{l}\text { (c) 2013 S. Karger AG, Basel } \\
1011-7571 / 13 / 0234-0295 \$ 38.00 / 0 \quad \text { Karger }\end{array}$ \\
E-Mail karger@karger.com & $\begin{array}{l}\text { This is an Open Access article licensed under the terms of the } \\
\text { www.karger.com/mpp }\end{array}$ \\
& $\begin{array}{l}\text { Creative Commons Attribution-NonCommercial 3.0 Un- } \\
\text { ported license (CC BY-NC) (www.karger.com/OA-license), } \\
\text { applicable to the online version of the article only. Distribu- } \\
\text { tion permitted for non-commercial purposes only. }\end{array}$
\end{tabular}

\section{Introduction}

Dental anxiety, or dental fear, is estimated to affect approximately $36 \%$ of the population, with a further $12 \%$ suffering from extreme dental fear [1]. This anxiety can have serious repercussions in terms of an individual's oral health, and it is considered to be a significant barrier to dental attendance [2] resulting in poor attendance. This is known as dental avoidance and can lead to poor oral health or the necessity for specialist dental care [3]. High dental anxiety has also been shown to influence the quality of life, with low oral health-related quality of life associated with high dental anxiety $[4,5]$. Indeed, $73 \%$ of participants in a study by McGrath and Bedi [5] reported believing that their oral health affected their life quality. If dental fear affects oral health status, dental attendance and the quality of life, then it is important for dental practitioners to understand the concepts and aetiology of dental fear, dental anxiety and/or dental phobia. Therefore, the aim of this review was to explore the peer-reviewed literature to answer the question: 'Why are people afraid of the dentist?'

\section{Literature Search}

Relevant literature was identified by searching the following on-line databases: PubMed, PsycInfo, the Cochrane Library and Google Scholar. Search terms included

Prof. Ruth Freeman

Dental Health Services Research Unit

9th Floor, School of Dentistry, University of Dundee, Park Place

Dundee DD1 4HN (UK)

E-Mail r.e.freeman@dundee.ac.uk 
subject heading and key words relevant to the causes and consequences of dental fear, dental anxiety and dental phobia. Publications from this search were examined and included if they explored specifically the causes and consequences of dental fear, dental anxiety or dental phobia.

\section{Concepts of Dental Fear, Dental Anxiety and Dental Phobia}

The first to adopt the term 'dental anxiety' was Coriat [6], who defined it as 'an excessive dread of anything being done to the teeth' with the result that 'any dental surgery, no matter how minor, or even dental prophylaxis, may be so postponed or procrastinated that the inroads of disease may affect the entire dental apparatus'. Coriat [6] suggested that a fear of the dentist was 'anticipatory anxiety' because it stemmed from a fear of real danger and an anticipated unknown danger.

The terms 'dental fear' and 'dental anxiety' are frequently used interchangeably, and the umbrella term 'dental fear and anxiety' (DFA) will be used in this paper. However, dental phobia is sometimes considered to be a separate concept; Lautch [7] defined dental phobia as 'a special kind of fear, out of proportion to the demands of the situation, which will not respond to reason, is apparently beyond voluntary control and leads to avoidance of dental treatment where this is really necessary'. Freeman [2] also stressed the importance of avoidance being present in dental phobia, stating that dental phobia cannot be diagnosed purely from the presence of dental anxiety the patient's history of dental experiences must also be considered.

With regard to 'dental phobia', current research suggests that it is actually one end of a continuum of dental anxiety $[1,8]$. As Freeman [8] noted, a continuum of dental anxiety explains the differences in intensity of anxiety, as well as the differences that exist regarding the underlying causes. Evidence for this continuum comes from the results of the Adult Dental Health Survey 2009 [1]. It was noted that over the previous two Adult Dental Health Surveys the prevalence of dental anxiety had decreased considerably (possibly due to improvements in pain reduction [9]) but the incidence of extreme dental fear, or dental phobia, had remained constant, suggesting that for those who are classified as 'dentally phobic' there are more complex underlying causes of their fear. The notion of a continuum is supported by the two dominant measures of dental anxiety: the Dental Anxiety Scale (DAS) [10] and the Modified Dental Anxiety Scale (MDAS) [11,
Table 1. Comparison of the two prominent classification definitions for specific phobias

Classification Definition of 'specific phobia' manual

DSM-IV 'Marked and persistent fear that is excessive or unreasonable, cued by the presence or anticipation of a specific object or situation... Exposure to the phobic stimulus almost invariably provokes an immediate anxiety response... The phobic situation is avoided or is endured with intense anxiety or distress.'

ICD-10
disorders in which anxiety is evoked only, or
predominantly, in certain well-defined situations
that are not currently dangerous. As a result these
situations are characteristically avoided or
endured with dread. (Specific phobias are)
phobias restricted to highly specific situations...
Though the triggering situation is discrete,
contact with it can evoke panic.'

12]. The MDAS has an empirically devised cut-off point where scores above a certain level indicate the possibility of dental phobia, rather than dental anxiety, as follows: 5-9 = not dentally anxious, $10-18$ = fairly dentally anxious, and 19-25 = very dentally anxious/dentally phobic [13].

In both the Diagnostic and Statistical Manual of Mental Disorders (DSM-IV) and the International Statistical Classification of Diseases and Related Health Problems 10th Revision (ICD-10) [14], there is no specific definition for dental anxiety; instead, it is understood as a specific phobia (table 1). One way to differentiate between dental anxiety and dental phobia is to consider the impact the anxiety has on normal functioning, i.e. if it interferes with an individual's occupation, or social activities, or if the individual is distressed by his/her anxiety then this individual would meet the DSM-IV criteria for a specific (dental) phobia [15].

One way of examining the relationship between function and dental phobia is to study the interaction of DFA and oral health status. In a longitudinal study following a large sample of adolescents in New Zealand from age 15 to 18 years, Kruger et al. [16] found that high dental anxiety was predictive of dental caries in adolescents; dentally anxious patients had the highest levels of caries severity among the sample. This finding was confirmed by an epidemiological study of 374 male army soldiers whose dental anxiety and dental status were measured [17]. 
Dentally anxious soldiers had significantly more carious teeth than those who were less anxious. In addition, Thom et al. [18] found that in a study of German participants with a specific (dental) phobia, as measured by the DSMIV, a quarter of participants' teeth were in a state of decay and required treatment. When compared with the general German population, those with extreme dental fear had a higher prevalence of decayed teeth. The above observations of the existence of oral health disparities in those with extreme dental fear [16-20] not only highlight the consequences of DFA for oral health function but also support the idea that a specific dental phobia exists [15].

\section{The Aetiology of DFA}

Locker et al. [19] studied the age of onset of dental anxiety in a survey of 1,420 adult participants, $16.4 \%$ of whom were assessed as being dentally anxious. Half of those who were dentally anxious reported that their dental fear started in childhood. This relationship between dental anxiety and childhood onset reinforces the need to understand the aetiology of dental fear in order to prevent the potential for oral disease in adulthood. This proposition is supported by ten Berge [20], who stated the importance of targeting children at risk for DFA. Indeed, when Akbay Oba et al. [21] examined the relationship between DFA and dental caries in 275 children, they reported that the number of decayed, missing or filled teeth increased as dental fear increased. This further highlights the importance of addressing the issue of DFA in children to prevent the negative effects on oral health.

To understand these aetiological factors, Eli et al. [22] assessed patient dental anxiety using the Dental Anxiety Survey, and psychological distress profiles were determined by the Symptom Check List (SCL-90). Patients were asked to complete a dentist evaluation questionnaire. It was shown that the best predictor of dental anxiety was the patient's evaluation of their present dentist followed by previous dental anxiety. The three SCL-90 dimensions of patient interpersonal sensitivity, anxiety and phobic anxiety correlate with present dental anxiety. Therefore, a patient's dental anxiety was negatively correlated with a positive evaluation of their dentist.

It is important, therefore, to understand each aetiological factor associated with DFA in terms of exogenous and endogenous sources of DFA in order to improve patients' oral health and quality of life and to increase dentists' awareness and understanding of the dentally anxious patient [9].

Dental Fear, Anxiety and Phobia

\section{Exogenous Sources of DFA}

The term 'exogenous' means that the source of an individual's anxiety is external, and it is understood by current research to be due to direct traumatic experiences or indirect vicarious experiences [16].

\section{Direct Previous Traumatic Experiences}

It has been reported that individuals with high levels of DFA often attribute their anxiety to their experience of a traumatic past dental event. Locker et al. [23] referred to this as 'conditioning via aversive treatment experience'. In a study of phobic patients [24], 61\% reported that their phobia stemmed from 'conditioning experiences'.

It has been suggested that when the traumatic dental episode occurs in childhood it has a lasting effect with regard to adult DFA. As previously mentioned, Locker et al. [19] found that half of those suffering from DFA developed their fear or anxiety in childhood, highlighting the need to understand how children acquire DFA. ten Berge et al. [25] examined how children acquire dental fear, specifically with regard to invasive treatment experiences. Regression analysis showed that there was a significant relationship between child DFA and the number of extractions a child had experienced; suggesting that one of the causes of DFA was invasive dental treatment. An interesting additional finding by ten Berge et al. [25] was that children who had experienced more check-up visits before they experienced their first curative treatment (i.e. they had a longer history of non-invasive experiences) reported low levels of dental fear. This suggests that the longer the child continues to have a positive experience when visiting the dentist the less likely they are to become dentally fearful whenever they do eventually have a negative experience, referred to as latent inhibition.

An important part of the child dental experience is the interaction with dental staff, yet this is a relatively underresearched topic in terms of dental anxiety. However, research in this area suggests one possible way of reducing dental anxiety, by highlighting specific behaviours that increase or reduce anxiety. Zhou et al. [26] collected research from 11 publications in a systematic review examining the impact of dental care professionals' clinical behaviours on child DFA. A relationship existed between dental staff behaviour and child DFA, with punishing behaviours associated with high child DFA. To reduce DFA, they suggested that practitioners adopt an empathic communication style, verbal explanation and reassurance.

Of particular importance when discussing past child dental experiences is the role memory plays in maintain- 
ing DFA. Kent [27] examined dental patients' memory of pain by comparing patients' remembered pain 3 months after treatment with their expected and experienced pain. Kent [27] found that there was a closer association between remembered and expected pain than there was between remembered and experienced pain. This association was particularly strong in patients who scored high on the DAS. Kent hypothesized that dental anxiety might be maintained because the anxious patients have inaccurate memories of the pain they experienced during treatment. The view of Kent [27] was supported by Freeman [28], who demonstrated that memories of unpleasant past dental experiences were greater in dentally anxious patients than in non-anxious patients, with dentally anxious patients reporting more experiences of traumatic dental events, thereby indicating that the cause of DFA is more complex than simply a negative past dental experience.

Humphris and King [29] examined the impact of previous distressing experiences upon dental anxiety. One thousand and twenty-four students participated and completed the MDAS and an assessment of their susceptibility (Level of Exposure-Dental Experiences Questionnaire; LOE-DEQ) [30]. The authors found that $11 \%$ of the sample reported high dental anxiety. The local anaesthetic injection was the most feared item. With regard to past traumatic dental treatment, participants who reported a distressing experience were two and a half times more likely to experience high dental anxiety [29]. Humphris and King [29] stated that experience of a dental treatment trauma was most predictive of DFA.

Moreover, Humphris and King [29] showed that other distressing experiences could be displaced onto dental treatment resulting in DFA. They reported that sexual assault victims were almost two and a half times more likely to report high dental anxiety compared to participants who had not experienced sexual assault. Similarly, Leeners et al. [31] found that women with an experience of sexual assault reported DFA related to lying flat in the dental chair, and they found that those with a history of sexual abuse had a more pronounced gagging reflex and higher DFA [32]. These findings highlight the point that it is not just previous, negative dental experiences that can cause subsequent DFA but also other traumatic experiences far removed from the dental surgery.

\section{Indirect Vicarious Experiences}

Vicarious learning is defined as indirect learning from role models, such as family members or peers, or external sources such as the media [22].
In a systematic review and meta-analysis of 43 experimental studies about parental and child dental fear, Themessl-Huber et al. [33] confirmed that there was a significant relationship between child and parental dental fear. The interplay between both the mother's and the father's dental fear was further examined and it was found that, in a family, both the mother's dental anxiety and the father's dental anxiety are significant predictors of child DFA [34]. Similarly, Locker et al. [19] found an association between the onset age of dental anxiety and a family history of dental anxiety, which would confirm that vicarious learning is a potential cause of DFA. Specifically, Locker et al. [19] found that $56 \%$ of participants who reported child onset dental anxiety had a parent or sibling who also suffered anxiety about dental treatment. This suggests that, as children, these participants indirectly learned their anxious response to dental treatment by observing the behaviour of those around them. The authors noted that the association with a family history of dental anxiety only existed with child onset anxiety, which confirmed the findings of Öst [35] that child onset phobias were more likely to develop through vicarious learning compared to those phobias that have their onset in adulthood.

In a qualitative study of DFA in children and adolescents, Gao et al. [36] analysed videos from YouTube about dentistry. Twenty-seven videos that involved 32 children and adolescents were analysed for the 'manifestations and impacts of dental fear and anxiety' and the 'origins of dental fear and anxiety'. 'Influence of parents and peers' emerged as an important point in DFA causation. For children parental teasing and for adolescents hearing stories from their friends about negative dental experiences were the root of the development of DFA [36]. Influences from friends and family members are therefore considered to be the most relevant when considering DFA in children [33], whereas for DFA in adolescents it is the impact of the peer group which is believed to be more important $[36,37]$.

Examining the impact of the media upon DFA, Oosterink et al. [38] asked 1,464 participants to complete the LOE-DEQ measure, which contains questions about their experiences of frightening stories told in the media about dental treatment. They found no significant difference between those who had and had not been exposed to frightening stories in the media. In contrast, Humphris and King [29] found that individuals with high DFA were almost two and a half times more likely, compared to the rest of their sample, to have heard about or seen frightening stories about dental treatment in the media. Therefore, 
the evidence base concerning the influence of vicarious learning and the impact of the media remains equivocal.

\section{Endogenous Sources of DFA}

The term 'endogenous' relates to the idea that individuals are dentally anxious for internal reasons, such as personality traits. Locker et al. [19] has referred to internal aetiological factors as a 'constitutional vulnerability to (dental) anxiety disorders'.

\section{Heritability}

Ray et al. [39] tested the hypothesis of a genetic component of DFA. In their longitudinal study of over 2,000 twins (the Swedish Twin Study of Child and Adolescent Development), the authors measured DFA and dental fear intensity. These measures took the form of 3 dental fear questions answered by selecting yes or no, and a single question about the intensity of the dental fear. Data were collected when participants were 13-14 years old and again 3 years later. A genetic component in dental fear/anxiety was found, and the heritability was shown to be higher in girls than in boys. No such gender difference was found for dental fear intensity. These findings not only fill a gap in the literature but they also provide an interesting addition to theories of the antecedents of DFA.

\section{Personality Traits}

The predominant model of personality, in current psychological research, is the 5 -factor model which divides personality into 5 traits: (a) openness to experience, (b) conscientiousness, (c) extraversion, (d) agreeableness and (e) neuroticism $[40,41]$. Neuroticism and extraversion are the two traits that are predominantly related to DFA [40]. Costa and McCrae [41] define these traits as follows:

- Extraversion involves warmth, excitement seeking and assertiveness.

- Neuroticism involves aspects of anxiety, self-consciousness, hostility and depressive symptoms.

Neuroticism has been shown to have a strong association with a propensity to experience anxiety [42]. Therefore, in a study of 880 students at 4 Finnish universities, participants' dental anxiety and the above 5 personality traits were measured. Halonen et al. [40] reported that dental anxiety was significantly and positively correlated to neuroticism, and significantly but negatively correlated to extraversion. These results suggest that individuals who are highly neurotic or introverted are more likely to experience dental anxiety.

\section{Cognitive Ability}

In a study examining anxiety in a dental setting, 40 children (age 8-16 years) who did not have a previous experience of visiting the dentist had their intelligence measured by the Wechsler Intelligence Scale of Children (WISC III). Toledano et al. [43] found that children with high intelligence quotients showed less anxiety than others at their first visit to the dentist. Blomqvist et al. [44] expanded on this research by measuring the relationship between cognitive ability (measured by the WISC III) and specifically DFA (measured by the Children's Fear Survey Schedule Dental Subscale) in 70 children. They found a significant negative correlation between DFA and verbal intelligence. No other significant relationships were found between DFA and other aspects of intelligence. This finding suggests that children with a high verbal intelligence suffer from less dental anxiety. This may be understood by considering how valuable being able to express and ventilate anxious feelings and explain coping strategies may be when entering a stressful environment such as a visit to the dentist [44].

\section{Consequences of DFA for Dental Practice}

The relationship between DFA and avoidance has been described as a 'vicious cycle' $[45,46]$ or, as Klepac et al. [47] stated: the 'possible confounding of oral health and fear level is one manifestation of the vicious cycle ubiquitous in neglected health concerns, wherein neglect leads to increased health concerns that render avoidance more likely, etc.' This hypothesis, first proposed by Berggren [45] in 1984, suggests that DFA leads to avoidance of dental care, which results in neglect of dental treatment and subsequently poor oral health. This is compounded by feelings of embarrassment [48] and shame, as well as by the likelihood that when a dentally anxious patient attends after a long period of avoidance they will need more invasive treatment [3] which has the potential to reinforce DFA and further, future avoidance (fig. 1).

The model of Berggren [45] of the vicious cycle has been supported by recent studies that have sought to test and expand this theory $[46,50]$. De Jongh et al. [46] validated the model of Berggren [45] by demonstrating that the deterioration of dental health status exacerbated the effects of dental avoidance, resulting in poorer oral health status, together with increased negativity associated with receiving dental treatment. 


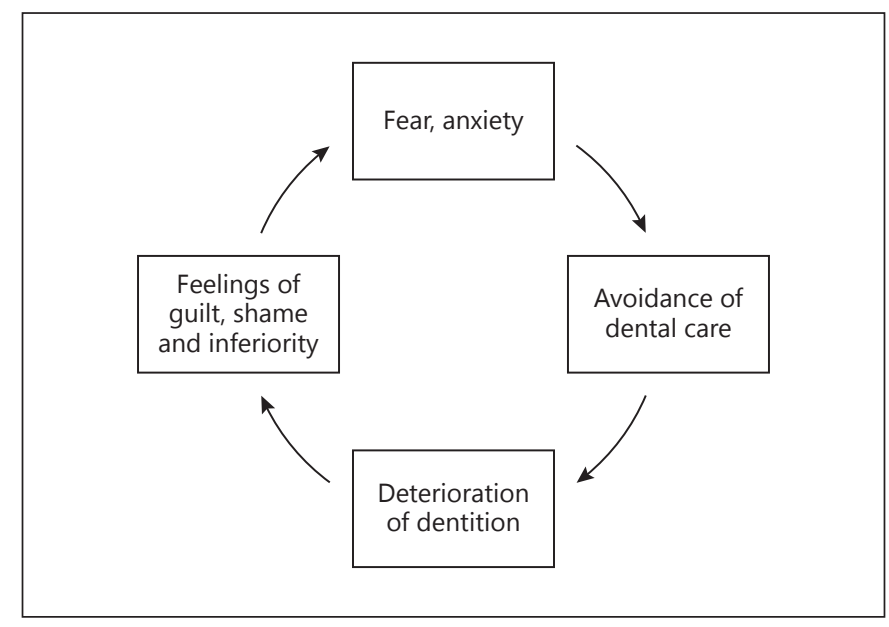

Fig. 1. The vicious cycle of dental anxiety of Berggren $[48,49]$.

More recently, Armfield [50] considered the vicious cycle by measuring DFA, the frequency of dental visits and treatment needs in 1,036 dentate Australians. He found that $39 \%$ of people with moderate to high dental fear fit the cycle of 'avoiding dental visiting because of fear, having treatment need and visiting for a problem' compared to only $1 \%$ of people without dental fear, thereby supporting the vicious cycle model, with dental fear acting as a determinant of dental avoidance.

Despite the evidence supporting the impact of dental anxiety upon dental attendance, the authors $[45,46,50]$ did not examine the relationship between previous frightening dental treatment experiences and the onset and maintenance of dental anxiety. Moreover, they did not provide an explanation for the observation that not everyone who has an unpleasant treatment experience enters the vicious cycle of dental anxiety.

Willumsen et al. [51] examined this in more detail. She posited an internal vicious cycle in which she hypothesized that patients perceive dental treatment as threatening. In response, patients experience increasing muscular tension and increased blood pressure and sweating, which further increases their dental anxiety. These physical sensations may be perceived as a threat to the patient's internal world, leading to feelings of panic and anxiety. This internal vicious cycle and misinterpretation of bodily sensations is a modification of Clark's cognitive model of panic [52] in which panic attacks are said to be caused by a 'catastrophic misinterpretation' of sensations such as palpitations or dizziness as being symptoms of a more serious condition.

\section{Conclusions and Practice Implications}

Dental anxiety and dental phobia represent points on a continuum and may reflect complex psychological problems that have significant effects on the lives of the individuals that suffer from them, whether they cause avoidance, increased dental caries or poor oral health-related quality of life. Therefore, it is necessary to consider how best to treat dental anxiety and phobia to prevent poor oral health in the future. As De Jongh et al. [53] noted, clinical experience and data from research suggests that general dental practitioners are capable of effectively treating patients with dental anxiety, but when a patient is phobic they should be referred to secondary level care such as psychological or pharmacological management.

There are clearly many different aetiological factors in the development of DFA, with evidence supporting theories of exogenous and endogenous causes such as past experiences, role models, the media, genetics, personality, and intelligence. An individual may have had a negative experience of visiting the dentist in the past, with evidence suggesting that DFA is more likely to have occurred in childhood, may have known someone who had a past negative experience, or may have the kind of personality traits that make him/her more likely than normal to be susceptible to anxiety. A person may be afraid of the dentist for one or all of these reasons, or even due to an interaction between them. Indeed, an individual who is highly neurotic may be subsequently more vulnerable to a negative experience than someone who is highly extraverted. This was summarized succinctly by Liddell and Locker [54] when they stated that: 'It is impossible to say from this study whether the experiences were, in fact, very traumatic, or whether the subjects were more sensitive to them.'

This review has highlighted the complexity of the multifactorial aetiology of dental fear, anxiety and phobia. The implications for dental practice are associated with knowing the degree to which the patient's fears prevent dental attendance, the history of the patient's dental anxiety and how the role of exogenous and endogenous factors impact the patient's DFA. Revealing these important aetiological factors will allow the dentist to tailor her/his treatment to the dental anxiety needs of the patient and thereby reduce patient fear and diminish workplace stress. 


\section{References}

1 Hill KB, Chadwick B, Freeman R, et al: Adult Dental Health Survey 2009: relationships between dental attendance patterns, oral health behaviours and the current barriers to dental care. Br Dent J 2013;214:25-32.

-2 Freeman R: Barriers to accessing dental care: patient factors. Br Dent J 1999;187:141-144.

3 Boyle CA, Newton T, Milgrom P: Who is referred for sedation for dentistry and why? $\mathrm{Br}$ Dent J 2009;206:E12.

4 McGrath C, Bedi R: Measuring the impact of oral health on quality of life in Britain: using OHQoL-UK(W). J Public Health Dent 2003; 63:73-77.

5 McGrath C, Bedi R: The association between dental anxiety and oral health-related quality of life in Britain. Community Dent Oral Epidemiol 2004;32:67-72.

6 Coriat IH: Dental anxiety: fear of going to the dentist. Psychoanal Rev 1946;33:365-367.

7 Lautch H: Dental phobia. Br J Psychiatry 1971;119:151-158.

8 Freeman R: Points of care: question 1. J Can Dent Assoc 2005;71:341-342.

9 Freeman R: Dental anxiety: a multifactorial aetiology. Br Dent J 1985;159:406-408.

10 Corah NL: Development of a dental anxiety scale. J Dent Res 1969;48:596.

11 Humphris GM, Morrison T, Lindsay SJ: The Modified Dental Anxiety Scale: validation and United Kingdom norms. Community Dent Health 1995;12:143-150.

12 Humphris GM, Freeman R, Campbell J, et al: Further evidence for the reliability and validity of the Modified Dental Anxiety Scale. Int Dent J 2000;50:367-370.

13 Humphris GM, Crawford JR, Hill K, et al: UK population norms for the modified dental anxiety scale with percentile calculator: adult dental health survey 2009 results. BMC Oral Health 2013;13:29.

14 International Statistical Classification of Diseases and Related Health Problems 10th Revision. http://apps.who.int/classifications/icd10/ browse/2010/en.

15 Kvale G, Raadal M, Vika M, et al: Treatment of dental anxiety disorders: outcome related to DSM-IV diagnoses. Eur J Oral Sci 2002; 110:69-74.

16 Kruger E, Thomson WM, Poulton R, et al: Dental caries and changes in dental anxiety in late adolescence. Community Dent Oral Epidemiol 1998;26:355-359.

17 Eitner S, Wichmann M, Paulsen A, et al: Dental anxiety - an epidemiological study on its clinical correlation and effects on oral health. J Oral Rehabil 2006;33:588-593.

18 Thom A, Sartory G, Jöhren P: Comparison between one-session psychological treatment and benzodiazepine in dental phobia. J Consult Clin Psychol 2000;68:378-387.

19 Locker D, Liddell A, Dempster L, et al: Age of onset of dental anxiety. J Dent Res 1999;78: 790-796.
20 ten Berge M: Dental Fear in Children: Prevalence, Etiology and Risk factors. Amsterdam, Universiteit van Amsterdam, 2001, pp 69-80.

21 Akbay Oba A, Dülgergil CT, Saroğlu Sönmez I: Prevalence of dental anxiety in 7 - to 11-yearold children and its relationship to dental caries. Med Princ Pract 2009;18:453-457.

22 Eli I, Uziel N, Baht R, et al: Antecedents of dental anxiety: learned responses versus personality traits. Community Dent Oral Epidemiol 1997;25:233-237.

23 Locker D, Thomson WM, Poulton R: Psychological disorder, conditioning experiences and the onset of dental anxiety in early adulthood. J Dent Res 2001;80:1588-1592.

24 Öst L, Hugdahl K: Acquisition of blood and dental phobia and anxiety response patterns in clinical patients. Behav Res Ther 1985;23: 27-34.

25 ten Berge M, Veerkamp JSJ, Hoogstraten J: The etiology of childhood dental fear: the role of dental and conditioning experiences. Anxiety Disord 2002;16:321-329.

26 Zhou Y, Cameron E, Forbes G, et al: Systematic review of the effect of dental staff behaviour on child dental patient anxiety and behaviour. Patient Educ Couns 2011;85:4-13.

27 Kent G: Memory of dental pain. Pain 1985;21: 187-194.

28 Freeman R: The role of memory on the dentally anxious patient's response to dental treatment. Ir J Psychol Med 1991;8:110-115.

29 Humphris GM, King K: The prevalence of dental anxiety across previous distressing experiences. J Anxiety Disord 2011;25:232-236.

- 30 Oosterink FMD, De Jongh A, Hoogstraten J, et al: The Level of Exposure-Dental Experiences Questionnaire (LOE-DEQ): a measure of severity of exposure to distressing dental events. Eur J Oral Sci 2008;116:353-361.

31 Leeners B, Stiller R, Block E, et al: Consequences of childhood sexual abuse experiences on dental care. J Psychosom Res 2007;62: 581-588.

32 Uziel N, Bronner G, Elran E, et al: Sexual correlates of gagging and dental anxiety. Community Dent Health 2012;29:243-247.

33 Themessl-Huber M, Freeman R, Humphris $G$, et al: Empirical evidence of the relationship between parental and child dental fear: a structured review and meta-analysis. Int J Paediatr Dent 2010;20:83-101.

-34 Lara A, Crego A, Romero-Maroto M: Emotional contagion of dental fear to children: the fathers' mediating role in parental transfer of fear. Int J Paediatr Dent 2012;22:324-330.

- 35 Öst L: Age of onset of different phobias. J Abnorm Psychol 1987;96:223-229.

36 Gao X, Hamzah SH, Yiu CKY, et al: Dental fear and anxiety in children and adolescents: qualitative study using YouTube. J Med Internet Res 2013;15:e29.
37 Steinberg L, Monahan KC: Age differences in resistance to peer influence. Dev Psychol 2007;43:1531-1541.

38 Oosterink FMD, de Jongh A, Aartman IHA: Negative events and their potential risk of precipitating pathological forms of dental anxiety. J Anxiety Disord 2009;23:451-457.

39 Ray J, Wide Boman U, Bodin L, et al: Heritability of dental fear. J Dent Res 2010;89:297301.

40 Halonen H, Salo T, Hakko H, et al: Association of dental anxiety to personality traits in a general population sample of Finnish university students. Acta Odontol Scand 2012;70 96-100.

41 Costa PT Jr, McCrae RR: NEO PI-R Professional Manual. Odessa, Psychological Assessment Resources, 1992.

42 Matthews G, Deary IJ, Whiteman MC: Personality Traits, ed 2. Cambridge, Cambridge University Press, 2003, pp 344-350.

43 Toledano M, Osorio R, Aguilera FS, et al: Children's dental anxiety: influences of personality and intelligence factors. Int J Paediatr Dent 1995;5:23-28.

44 Blomqvist M, Ek U, Fernell E, et al: Cognitive ability and dental fear and anxiety. Eur J Oral Sci 2013;121:117-120.

45 Berggren U: Dental fear and avoidance: a study of etiology, consequences and treatment. Göteborg, Göteborg University, 1984.

46 De Jongh A, Schutjes M, Aartman IHA: A test of Berggren's model of dental fear and anxiety. Eur J Oral Sci 2011;119:361-365.

47 Klepac RK, Dowling J, Hauge G: Characteristics of clients seeking therapy for the reduction of dental avoidance: reactions to pain. J Behav Ther Exp Psychiatry 1982;13:293-300.

48 Moore R, Brødsgaard I, Rosenberg N: The contribution of embarrassment to phobic dental anxiety: a qualitative research study. BMC Psychiatry 2004;4:10-20.

49 Berggren U, Meynert G: Dental fear and avoidance - causes, symptoms and consequences. J Am Dent Assoc 1984;109:247-251.

50 Armfield JM: What goes around comes around: revisiting the hypothesized vicious cycle of dental fear and avoidance. Community Dent Oral Epidemiol 2013;41:279-287.

51 Willumsen T, Haukebø K, Raadal M: Aetiology of dental phobia; in ÖM L, Skaret E (eds): Cognitive Behavioural Therapy for Dental Phobia and Anxiety. Chicester, Wiley-Blackwell, 2013, pp 45-59.

52 Clark DM: A cognitive approach to panic. Behav Res Ther 1986;24:461-470.

53 De Jongh A, Adair P, Meijerink-Anderson M: Clinical management of dental anxiety: what works for whom? Int Dent J 2005;55:73-80.

54 Liddell A, Locker D: Changes in levels of dental anxiety as a function of dental experience. Behav Modif 2000;24:57-68. 